\title{
Digital Rehabilitation for Acute Ankle Sprains: Prospective Longitudinal Cohort Study
}

Fernando D Correia ${ }^{1,2}, \mathrm{MD}, \mathrm{PhD}$; Maria Molinos ${ }^{3}, \mathrm{PhD}$; Carlos Neves ${ }^{3}, \mathrm{PT}$; Dora Janela ${ }^{3}, \mathrm{PT}$; Diana Carvalho ${ }^{3}$, PT; Sara Luis ${ }^{3}$, PT; Gerard E Francisco ${ }^{4,5}$, MD; Jorge Lains ${ }^{6,7}$, MD; Virgilio Bento ${ }^{3}$, PhD

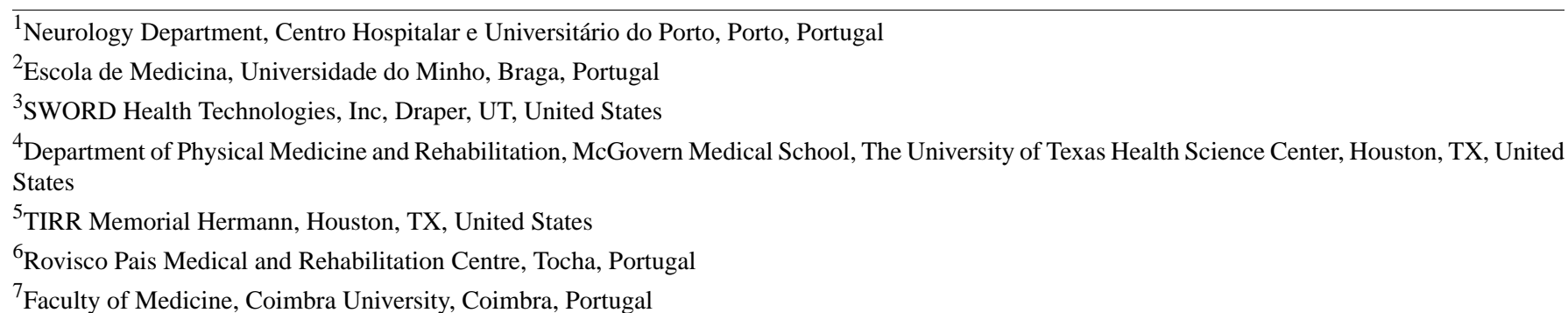

Corresponding Author:

Fernando D Correia, MD, PhD

Neurology Department

Centro Hospitalar e Universitário do Porto

Largo do Prof Abel Salazar

Porto, 4099-001

Portugal

Phone: 351966557789

Email: fanacorreia@gmail.com

\section{Abstract}

Background: Ankle sprains are one of the most prevalent soft-tissue injuries worldwide. Physical therapy, especially progressive exercise, has proven effective in improving function, while preventing recurrence.

Objective: We aim to present the results of a fully remote and digitally guided rehabilitation program for acute ankle sprains.

Methods: We performed a prospective longitudinal cohort study of individuals eligible for workers' compensation, who were referred for digital rehabilitation therapy for a sprained ankle. Therapeutic exercise sessions were to be performed independently by the patient at home using the biofeedback device provided by SWORD Health. Primary endpoints were the change in self-reported Numerical Pain Rating Scale (NPRS) and Foot and Ankle Ability Measure-activities of daily living (FAAM-ADL) and FAAM-Sports scores. Participants were assessed at baseline, end of the program, and 6 months after program completion. Secondary outcomes included digital therapy dosage, pain and fatigue during sessions, and satisfaction.

Results: In total, 93 (89.4\%) patients completed the program and 79 (76.0\%) were available for follow-up. Changes in the primary outcomes between baseline and the 6-month follow-up were both significant $(P<.001)$ and clinically meaningful: mean difference of -2.72 points (95\% CI -3.31 to -2.13 ) on the NPRS (49.8\% reduction), 21.7 points (95\% CI 17.13-26.27) on the FAAM-ADL (41.1\% increase), and 37.8 points (95\% CI 30.45-45.15) on the FAAM-Sports (151.8\% increase). Longer waiting periods between the accident date and treatment initiation were found to negatively impact functional status at baseline and at the end of the program, triggering an extension in the program duration. The total training volume (12.5 hours, SD 10.5 hours) was similar to that of other interventions for ankle sprains, but the dosage per week was much higher (2.4 hours per week, SD 0.87 hours per week). The mean patient satisfaction score was 8.8 (SD 1.57) out of 10. Among program completers, 83.9\% attained full recovery and were discharged with no residual disability.

Conclusions: Being far less demanding in terms of human resources, the digital program presented constituted a viable, clinically effective, and convenient solution for ankle sprain rehabilitation, particularly during the pandemic. This is the first study presenting a fully remote home-based rehabilitation program for acute ankle sprains, with patients achieving sustained long-term results. This was a prospective cohort study and, as such, did not include a control group, but the results appear comparable to those published for face-to-face interventions.

Trial Registration: ClinicalTrials.gov NCT04819022; https://clinicaltrials.gov/ct2/show/NCT04819022 
(JMIR Rehabil Assist Technol 2021;8(3):e31247) doi: 10.2196/31247

\section{KEYWORDS}

acute ankle sprains; physical rehabilitation; home-based digital rehabilitation; digital therapy; rehabilitation; sprain; digital health; therapy; rehabilitation; prospective; longitudinal; cohort; ankle; soft tissue; physical therapy; pain; outcome; fatigue

\section{Introduction}

Ankle sprains are one of the most prevalent soft-tissue injuries, with an estimated incidence of 2.15 per 1000 person-years in the United States [1] and 5-7 per 1000 person-years in Europe [2]. They are more common in the second and third decades of life [3], but only about half are associated with sports participation, suggesting that they may affect individuals with different physical activity levels [1].

Given their high incidence, ankle sprains have an important socioeconomic impact, mainly from indirect costs [4,5]. Overall costs range from US \$1809-\$5271 per patient, with direct costs representing US \$292-\$2268 [6]. Other studies estimate that indirect costs make up for $70 \%-90 \%$ of the total costs $[5,7]$.

It has also been observed that $12 \%-47 \%$ of all ankle sprains are recurrent [8-12], and at least one-third of individuals experience residual symptoms [13-15]. In fact, evidence suggests that individuals with previous ankle sprain are at an approximately 3.5 times greater risk of recurrence [1], and that up to $45 \%$ of patients report an incomplete recovery 3 years after injury [16].

Ensuring complete recovery and a decreased risk of reinjury are therefore of paramount importance. Physical therapy, especially progressive exercise, has been shown to not only improve function [17-23] but also prevent recurrence [17,24,25]. Effectiveness seems to improve with intensity, especially in doses of more than 900 minutes of total exercise time [18].

Notwithstanding, access to physical therapy interventions remains a challenge, owing to physical mobility and transportation limitations [26-29]. Home-based interventions have been studied as alternatives. However, despite being associated with improved outcomes [30], a systematic review reported diminished gains in pain and physical capacities when compared to supervised rehabilitation [31]. Additionally, low compliance is a known issue [32].

A potential solution is telerehabilitation, which helps alleviate time, travel, and access barriers, while potentiating intensity and satisfaction [33-36]. Another advantage of telerehabilitation is the minimal person-to-person contact, which is particularly relevant in the actual pandemic context. Indeed, there is growing research on its application in a variety of musculoskeletal conditions [33,34,37-39], with promising results in comparison with conventional care $[35,40]$. Studies have also demonstrated that remote patient assessment is technically feasible and valid for ankle joint disorders [36]. However, there is still a lack of adoption of telerehabilitation [41] as well as intrinsic limitations regarding access to technology and the need for real-time availability of a physical therapist.

To overcome this limitation, technological approaches allowing independent home-based rehabilitation have been developed, but these are still experimental, and clinical validation is scant
[42]. In previous clinical studies, we demonstrated the feasibility and safety of digitally delivered rehabilitation programs after total knee and hip replacement [43-45], as well as the ability to maximize clinical outcomes over conventional physical therapy through the same technology.

New digital programs aimed at treating other conditions have since been developed. This paper presents the results of a prospective, consecutive cohort of patients undergoing a fully remote rehabilitation program for acute ankle sprain.

\section{Methods}

\section{Study Design}

This is a prospective, longitudinal cohort study aimed to assess the clinical outcomes of digital rehabilitation programs provided by SWORD Health.

\section{Participants}

Individuals eligible for workers' compensation under health plans, which have entered into a commercial agreement with SWORD Health, acting as an in-network provider of physical therapy services, were recruited. Patients were initially assessed by their orthopedic surgeon and referred for physical therapy after confirmation of an ankle sprain (based on clinical and imaging findings). Referral to in-network providers of physical therapy was managed administratively, with the possibility of explicit referral to the digital program by the orthopedic surgeon.

\section{Rehabilitation Program}

The plan of care was based on therapeutic exercise sessions to be performed independently by the patient at home using the biofeedback device provided by SWORD Health, in accordance with the protocol presented in Multimedia Appendix 1. Patients were instructed to perform 1 exercise session per day. The plan was adapted by the treating physician in articulation with the physical therapist as needed. Program duration and patient discharge were determined by the treating physician.

\section{Study Outcomes}

The primary outcome was the change in the self-reported Numerical Pain Rating Scale (NPRS) score (0-10), as well as the change in the Foot and Ankle Ability Measure (FAAM) [46] - for activities of daily living (FAAM-ADL) and sports (FAAM-Sports) between baseline and the 6-month follow-up. Patients were assessed for these outcomes at baseline, end of the rehabilitation program, and at 6 months, through an electronic survey. The NPRS was self-reported at each assessment survey with the question, "How would you rate your pain over the last 7 days - from 0 (no pain at all) to 10 (worst pain imaginable)?" 
Secondary outcomes included the following user experience-related outcomes, collected along the program by the digital therapist:

1. Treatment dosage: program duration (days), number of sessions per week, total number of sessions, minutes per session, and total exercising time (minutes and hours).

2. Average pain during sessions: self-reported at the end of each session; visual analogue scale (VAS) scores of 0-10;

3. Change in pain during sessions: last versus first VAS score for pain registered;

4. Average fatigue during sessions: self-reported at the end of each session; VAS scores of 0-10;

5. Change in fatigue during sessions: last versus first VAS score for fatigue registered;

6. Satisfaction: assessed at the end of the program with the question, "On a scale from 0 to 10 , how likely is it that you would recommend this intervention to a friend or neighbor?"

\section{Statistical Analysis}

To assess differences in primary and secondary outcomes among the 3 time points, a Bonferroni multiple comparison test was performed with time as a categorical variable. Both unadjusted and adjusted differences for covariates with 95\% CIs were estimated. Included covariates were age, gender, BMI, days to start treatment, grade of sprain, exercise level, and previous injury.

Linear mixed-effects models (LMM) were also utilized to assess participant change across NPRS, FAAM-ADL, and FAAM-Sports metrics from baseline to the end of the study. This type of model was chosen over a repeated-measures analysis of variance (ANOVA) since the former allows for a relaxation of model assumptions (ie, it does not assume that variances and covariances among groups are equal), a more flexible treatment of time (which is treated as a continuous variable and not a category), and makes it easier to include covariates (as additional fixed-effects) [47].
For each outcome, a model was created without including covariates (unadjusted) and including covariates (adjusted). Multiple imputation using 50 imputed data sets was used to account for attrition in each variable across time [48].

A bivariate correlation analysis was also performed to investigate covariates' association with outcomes.

A repeated-measures ANOVA was also performed for the primary outcomes with time as the within-subjects factor and grade of sprain (grades I-III per the guidelines of Lynch [49]) as the between-subjects factor. The same approach was used with program duration categories ( $<4$ weeks and $>4$ weeks) as the between-subjects factor.

LMM analysis was performed using R. All the other statistical analyses were performed using SPSS (version 17.0; SPSS Inc).

\section{Data Availability}

Deidentified individual participant data are provided in Multimedia Appendix 2.

\section{Results}

\section{Baseline Characteristics of Participants}

In total, 104 patients from 4 different recruitment sites and 26 different orthopedic surgeons were consecutively enrolled in SWORD Health's fully remote physical therapy program for ankle sprain between February and November 2020 (Figure 1). The dropout rate was $10.6 \%$ (11/104); 1 (1.0\%) patient subsequently refused all types of care proposed by the physician, $5(4.8 \%)$ dropped out owing to unknown reasons (missing exercise sessions and medical appointments), and 5 (4.8\%) did not adhere to the digital program. In total, $93(89.4 \%)$ patients completed the program, and $79(76.0 \%)$ were available for follow-up.

Participant's baseline characteristics are presented in Table 1. Baseline assessment of the outcome variables is summarized in Table 2. 
Figure 1. Flow chart for participant inclusion (left) and attrition (right). FAAM-ADL: Foot and Ankle Ability Measure-activities of daily living, FAAM-Sports: Foot and Ankle Ability Measure-sports, NPRS: Numerical Pain Rating Scale.

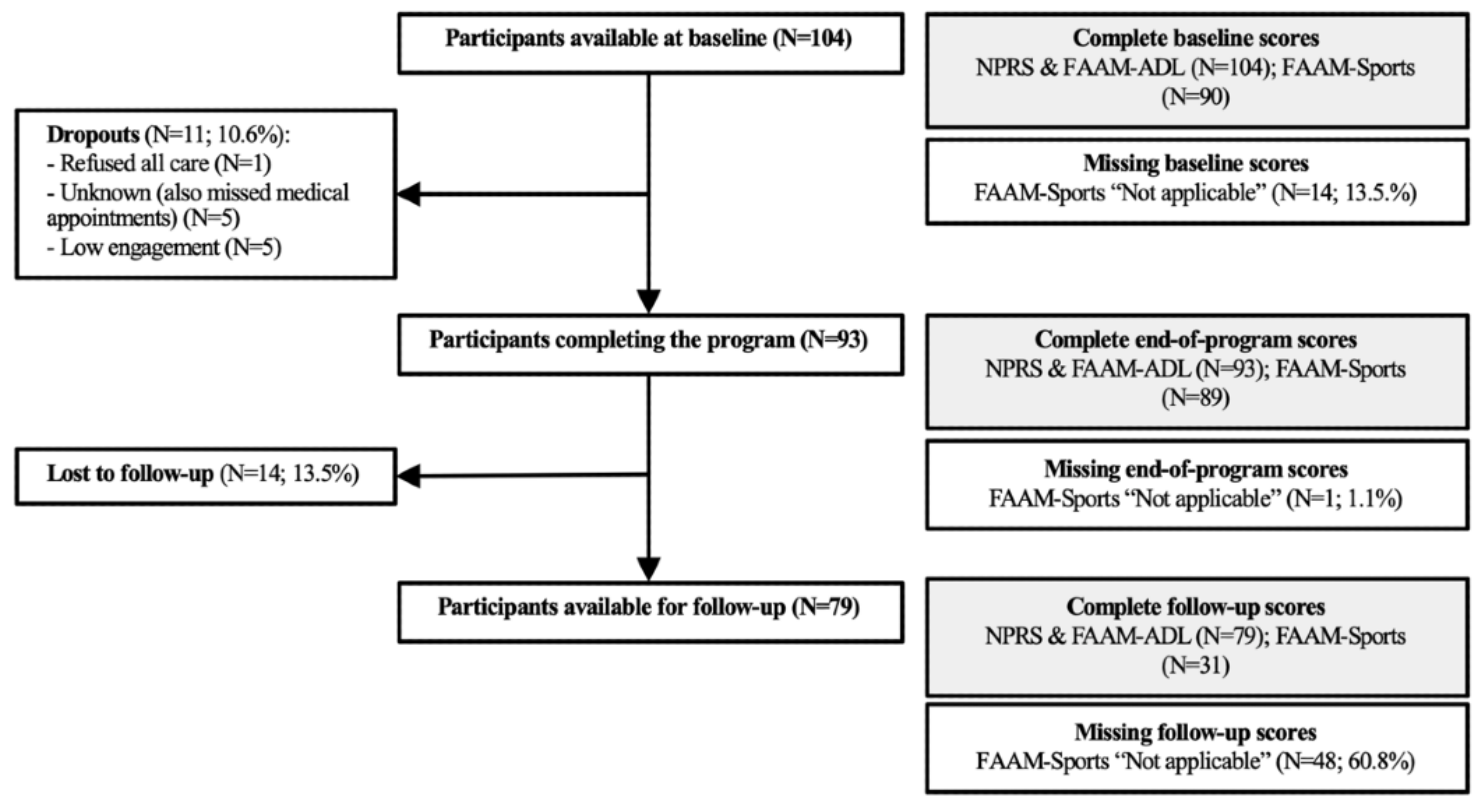


Table 1. Baseline characteristics of participants who finished the rehabilitation program ( $\mathrm{N}=93)$.

\begin{tabular}{|c|c|}
\hline Characteristic & Value \\
\hline Age (years), mean (SD) & $40.7(10.43)$ \\
\hline \multicolumn{2}{|l|}{ Age (years), n (\%) } \\
\hline$<25$ & $9(9.7)$ \\
\hline $25-40$ & $36(38.7)$ \\
\hline$>40$ & $48(51.6)$ \\
\hline Females, n (\%) & $50(53.8)$ \\
\hline BMI, mean (SD) & $27.8(4.98)$ \\
\hline \multicolumn{2}{|l|}{ BMI categories, n (\%) } \\
\hline Underweight $(<18.5)$ & $0(0)$ \\
\hline Normal (18.5-25) & $32(34.4)$ \\
\hline Overweight (25-30) & $32(34.4)$ \\
\hline Obese $(>30)$ & $29(31.2)$ \\
\hline Affected side: right, $\mathrm{n}(\%)$ & $47(50.5)$ \\
\hline \multicolumn{2}{|l|}{ Grade of ankle sprain, $n(\%)^{a}$} \\
\hline I & $53(57.0)$ \\
\hline II & $27(29.0)$ \\
\hline III & $10(10.8)$ \\
\hline \multicolumn{2}{|l|}{ Exercise level (hours per week), n (\%) } \\
\hline 0 & $36(38.7)$ \\
\hline $1-2$ & $30(32.3)$ \\
\hline $3-4$ & $16(17.2)$ \\
\hline$\geq 5$ & $11(11.8)$ \\
\hline Previous injury, $\mathrm{n}(\%)$ & $27(29)$ \\
\hline Previous surgery, n (\%) & 0 \\
\hline Time from injury date to treatment initiation (days), mean (SD) & $53.2(48.26)$ \\
\hline Time from referral to SWORD and treatment initiation (days), mean (SD) & $3.8(2.17)$ \\
\hline
\end{tabular}

${ }^{\mathrm{a}}$ Three observations are missing. 
Table 2. Estimates for patient-reported outcomes at baseline, end of the program, and 6-month follow-up assessment, unadjusted and adjusted for covariates.

\begin{tabular}{|c|c|c|}
\hline Time & Unadjusted for covariates, mean $(95 \% \mathrm{CI})$ & Adjusted for covariates ${ }^{\mathrm{a}}$, mean $(95 \% \mathrm{CI})$ \\
\hline \multicolumn{3}{|c|}{ Numerical Pain Rating Scale score } \\
\hline Baseline & $5.67(5.16-6.17)$ & $5.46(4.86-6.05)$ \\
\hline End of program & $3.67(3.16-4.17)$ & $3.46(2.87-4.06)$ \\
\hline 6-month follow-up & $2.92(2.42-3.43)$ & $2.73(2.15-3.32)$ \\
\hline \multicolumn{3}{|c|}{ Foot and Ankle Ability Measure-activities of daily living score } \\
\hline Baseline & $52.00(47.90-56.10)$ & $52.70(47.80-57.60)$ \\
\hline End of program & $63.50(59.50-67.60)$ & $64.30(59.50-69.20)$ \\
\hline 6-month follow-up & $73.50(69.50-74.40)$ & $74.40(69.60-79.20)$ \\
\hline \multicolumn{3}{|c|}{ Foot and Ankle Ability Measure-sports score } \\
\hline Baseline & $26.70(20.40-32.90)$ & $24.90(17.40-32.40)$ \\
\hline End of program & $46.20(39.90-52.40)$ & $44.60(37.20-52.00)$ \\
\hline 6-month follow-up & $64.30(58.00-70.50)$ & $62.70(55.30-70.10)$ \\
\hline \multicolumn{3}{|c|}{ Visual analogue scale for pain score $(0-10)$} \\
\hline Baseline & $3.98(3.56-4.40)$ & $3.52(2.74-4.30)$ \\
\hline End of program & $2.84(2.37-3.31)$ & $2.36(1.88-2.85)$ \\
\hline \multicolumn{3}{|c|}{ Visual analogue scale for fatigue score $(0-10)$} \\
\hline Baseline & $2.73(2.30-3.17)$ & $2.08(1.29-2.87)$ \\
\hline End of program & $2.77(2.25-3.30)$ & $2.15(1.61-2.69)$ \\
\hline
\end{tabular}

\footnotetext{
${ }^{a}$ Adjusted for age, gender, BMI, days to start treatment, grade of sprain, exercise level, and previous injury.
}

\section{Longitudinal Changes in Outcomes}

Table 2 presents the primary and secondary clinical outcomes. All patients showed significant improvement in NPRS, FAAM-ADL, FAAM-Sports, and VAS pain scores $(P<.001)$ from baseline to 6-month follow-up (Table 3).
Essentially, considering the minimal clinically important difference values established for FAAM subscales [50] (ie, 8 points for FAAM-ADL and 9 points for FAAM-Sports), the registered changes from baseline were also clinically meaningful. Overall, patients experienced reductions of 50\% and $33 \%$ in the NPRS and VAS pain scores, respectively, which can also be considered clinically significant. 
Table 3. Differences in adjusted ${ }^{\mathrm{a}}$ estimates upon multiple comparison at different time points assessed for the primary endpoints, pain, and fatigue sessions.

\begin{tabular}{|c|c|c|c|c|}
\hline Time-point comparisons & Estimate difference (95\% CI) & SE & $t$ test $(d f)$ & Bonferroni $P$ value \\
\hline \multicolumn{5}{|l|}{ Numerical Pain Rating Scale score } \\
\hline End of program vs baseline & $-1.99(-2.58$ to -1.40$)$ & 0.30 & $-6.63(184)$ & $<.001^{\mathrm{b}}$ \\
\hline 6-month follow-up vs baseline & $-2.72(-3.31$ to -2.13$)$ & 0.30 & $-9.04(184)$ & $<.001^{\mathrm{b}}$ \\
\hline 6-month follow-up vs end of program & $-0.73(-1.32$ to -0.14$)$ & 0.30 & $-2.42(184)$ & $.05^{\mathrm{b}}$ \\
\hline \multicolumn{5}{|c|}{ Foot and Ankle Ability Measure-activities of daily living score } \\
\hline End of program vs baseline & $11.60(7.03$ to 16.17$)$ & 2.33 & $5.00(184)$ & $<.001^{\mathrm{b}}$ \\
\hline 6-month follow-up vs baseline & $21.70(17.13$ to 26.27$)$ & 2.33 & $9.31(184)$ & $<.001^{\mathrm{b}}$ \\
\hline 6-month follow-up vs end of program & $10.00(5.43$ to 14.57$)$ & 2.33 & $4.31(184)$ & $<.001^{\mathrm{b}}$ \\
\hline \multicolumn{5}{|c|}{ Foot and Ankle Ability Measure-sports score } \\
\hline End of program vs baseline & $19.70(12.37$ to 27.03$)$ & 3.74 & $5.26(184)$ & $<.001^{\mathrm{b}}$ \\
\hline 6-month follow-up vs baseline & $37.80(30.45$ to 45.15$)$ & 3.75 & $10.10(184)$ & $<.001^{\mathrm{b}}$ \\
\hline 6-month follow-up vs end of program & $18.10(10.77$ to 25.43$)$ & 3.74 & $4.84(184)$ & $<.001^{\mathrm{b}}$ \\
\hline \multicolumn{5}{|l|}{ Visual analogue scale for pain score $(0-10)$} \\
\hline End of program vs baseline & $-1.16(-1.64$ to -0.67$)$ & 0.24 & $-4.72(89)$ & $<.001^{\mathrm{b}}$ \\
\hline \multicolumn{5}{|l|}{ Visual analogue scale for fatigue score $(0-10)$} \\
\hline End of program vs baseline & $0.07(-0.47$ to 0.61$)$ & 0.28 & $0.24(89)$ & .81 \\
\hline
\end{tabular}

${ }^{a}$ Adjusted for age, gender, BMI, days to start treatment, grade of sprain, exercise level, and previous injury.

${ }^{\mathrm{b}}$ Statistically significant at $P<.05$.

LMM analysis with 50 imputed data sets revealed that for all unadjusted models, significant effects of time were observed in the expected directions. This indicates that over the larger study timeline, participants reported significant improvements in NPRS, FAAM-ADL, or FAAM-Sports scores (Multimedia Appendix 3). Longitudinal changes in ankle function and pain perception are depicted in Figure 2. 
Figure 2. Linear mixed model showing the individual and aggregate longitudinal changes in the primary endpoints (FAAM-ADL, FAAM-Sports, and NPRS scores). Each thin line represents a participant, and the thick dotted line represents the average change across all participants. Covariates appearing in the model include age, gender, BMI, days to start treatment, grade of sprain, exercise level, and previous injury. Significant effects were found for covariates $(P<.05)$. FAAM-ADL: Foot and Ankle Ability Measure-activities of daily living, FAAM-Sports: Foot and Ankle Ability Measure-sports, NPRS: Numerical Pain Rating Scale.

A

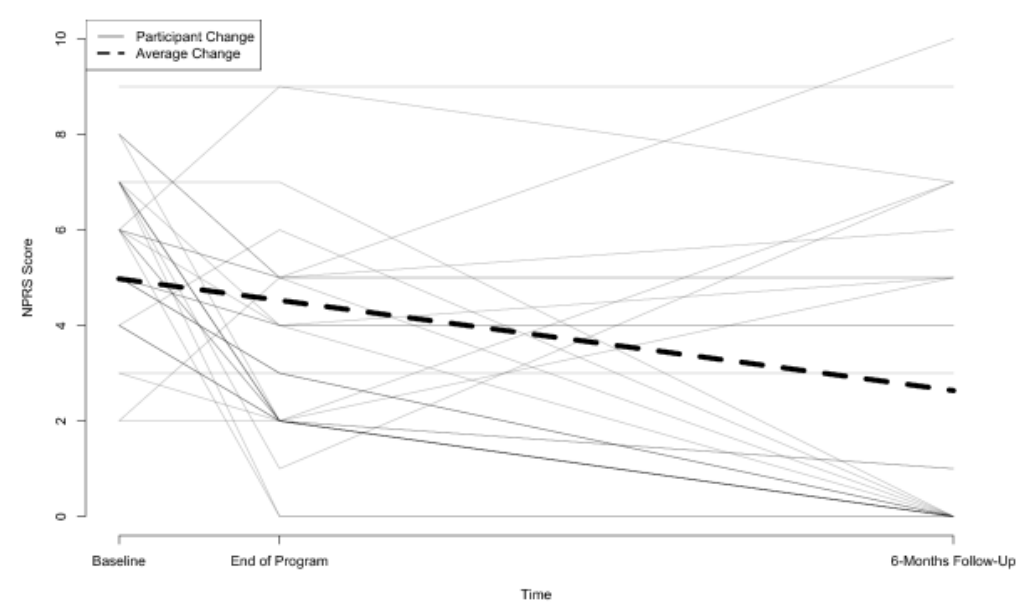

B

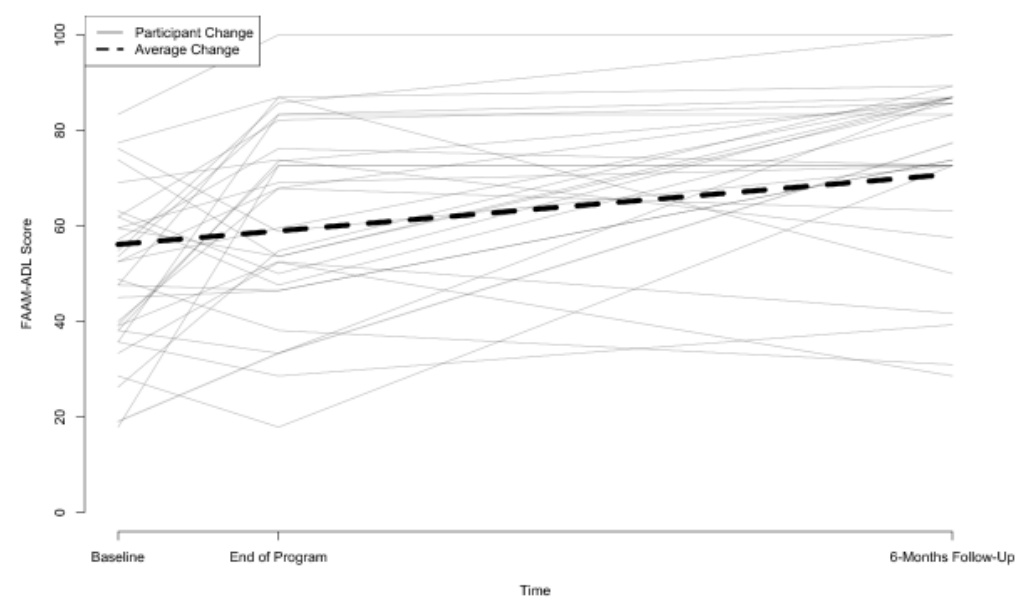

C

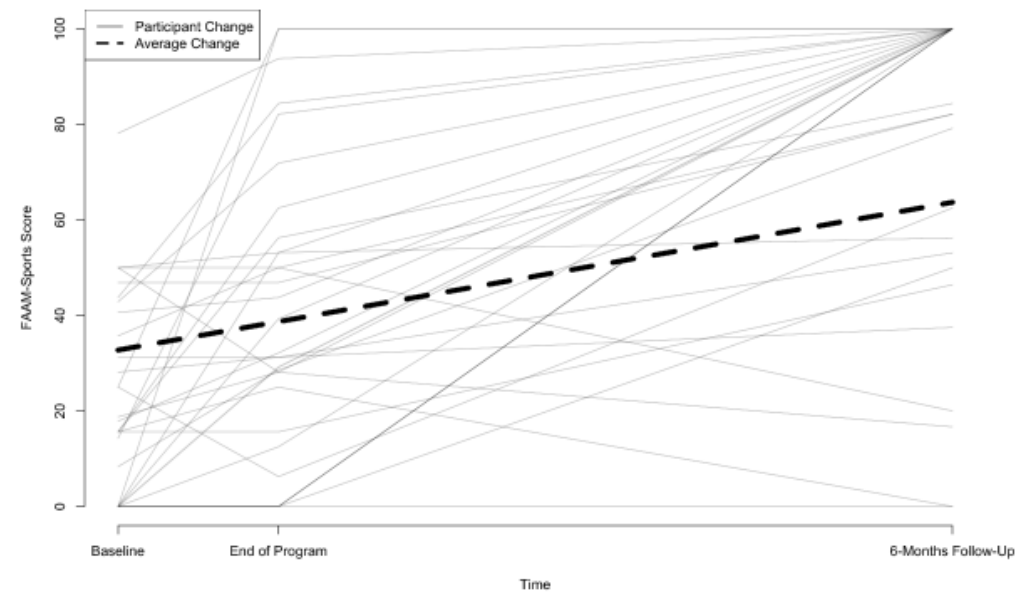

Similar effects of time were found for all adjusted models (Multimedia Appendix 3). Regarding NPRS scores, participants with a higher average BMI (estimate $=0.08 ; P=.04$ ) and those who took days to start treatment (estimate $=0.01 ; P=.02$ ) had significantly higher scores. A significant negative linear effect of sprain grade was also observed (estimate $=-1.00 ; P=.02$ ). No covariates significantly affected FAAM-ADL scores. Regarding FAAM-Sports scores, older participants showed significantly lower scores (estimate $=0.58 ; P=.03$ ). A significant negative quadratic effect of sprain grade was also observed (estimate $=0.01 ; P=.02$ ). 


\section{Usability-Related Outcomes}

\section{Compliance and Training Intensity}

Program completers performed on average 5.9 (SD 1.34, range 0.9-7.8) sessions per week (Table 4), with 39.8\% (37/93) of them performing 7 sessions per week, $45.2 \%$ (42/93) performing 5-6 sessions per week, and 15\% (14/93) performing less than 5 sessions per week. The mean program duration was 5.0 (SD 3.81, range 0.9-19.6) weeks, and the mean total exercise dosage was 750.6 (SD 630.25, range 77.1-2836.4) minutes, with $30 \%$ (28/93) of patients executing more than 900 minutes of exercise therapy, a threshold that has been described as being associated with better outcomes [18]. No significant correlation was found between total exercising time and primary endpoints.

\section{Session-Related Pain and Fatigue}

On their last session, patients reported significantly lesser pain than the initial session $(P<.001)$. Patient-reported fatigue did not change $(P=.81$; Table 3$)$, which reflects progression of session intensity/difficulty over time. Mean values for VAS pain and VAS fatigue scores during exercise sessions are presented in Table 4.

Table 4. System usability-related outcomes for patients who finished the rehabilitation program ( $\mathrm{N}=87)$.

\begin{tabular}{lll}
\hline Usability outcomes & Measure & Range \\
\hline Program duration (weeks) & Mean (SD) & $0.9-19.6$ \\
Sessions per week & $5.0(3.81)$ & $0.9-7.8$ \\
Total number of sessions & $5.9(1.34)$ & $3-115$ \\
Total exercising time (min) & $28.9(21.99)$ & $77.1-2836.4$ \\
Total exercising time (hours) & $750.6(630.25)$ & $1.3-47.3$ \\
Minutes per session & $12.5(10.50)$ & $12.0-37.2$ \\
Average pain during sessions (visual analogue scale for pain score, 0-10) & $24.7(5.86)$ & $0-7.7$ \\
Average fatigue during sessions (visual analogue scale for fatigue score, $0-10)$ & $3.5(1.45)$ & $0-6.8$ \\
Satisfaction $(0-10)^{\mathrm{a}}$ & $3.1(1.66)$ & $4-10$ \\
\hline
\end{tabular}

${ }^{\mathrm{a}}$ Two observations are missing.

\section{Satisfaction}

The mean satisfaction score was 8.8 (SD 1.57, range 4-10) points (Table 4). In total, 63.4\% (59/93) of patients answered "9" or "10," $23.7 \%$ (22/93) answered between "7" and "8," and 10.7\% (10/93) answered "6" or less.

\section{Disability and Return to Work}

Among those who finished the program, 83.9\% (78/93) of patients were classified by the treating physician as having obtained maximum medical improvement and no residual disability, while 12 (13\%) patients were rendered with permanent partial disability, $2(2 \%)$ with temporary total disability, and $1(1 \%)$ with permanent total disability.

In total, $48.4 \%(45 / 93)$ of completers returned to work before clinical discharge. Within those discharged with no residual disability, the majority $(53.8 \%, 42 / 78)$ did not return to work before clinical discharge, likely because of the shorter treatment period (median 2.8 weeks, IQR 4.04 weeks; range 0.86-9.57 weeks).

\section{Reinjury and Adverse Events}

The reinjury rate was $2.5 \% ; 2$ of the 79 available patients for follow-up reported ankle sprain recurrence as a result of a fall. One was a patient who had had 4 previous ankle sprains, and the other did not have a history of previous injury. Both had been discharged with no residual disability.

The adverse event rate was 3.2\% (Multimedia Appendix 4). One patient reported exacerbated ankle pain caused by long walks; one could not perform the sessions due to a suspected plantar fasciitis; and another reported intense lower back pain, limiting compliance with the exercise protocol. None were related to the digital intervention.

\section{Subgroup Analysis}

\section{Grade of Ankle Sprain}

This analysis confirmed a main effect of time for the 3 dimensions of NPRS $(P=.05)$ and FAAM-ADL $(P=.003)$ after 6 months. The results are presented in Tables 5 and 6 and Figure 3. 
Table 5. Repeated-measures analysis of variance for the primary outcomes based on the grade of sprain.

\begin{tabular}{lllllll}
\hline Outcome variable & Grade of sprain & & & & & \\
& Time & & Sprain grade & & \multicolumn{2}{c}{ Time $\times$ sprain grade } \\
& $F$ test $(d f 1, d f 2)$ & $P$ value & $F$ test $(d f 1, d f 2)$ & $P$ value & $F$ test $(d f 1, d f 2)$ & $P$ value \\
\hline $\begin{array}{l}\text { Numerical Pain Rating Scale score } \\
\begin{array}{l}\text { Foot and Ankle Ability Measure-activities of } \\
\text { daily living score }\end{array}\end{array}$ & $3.30(1.77,123.74)$ & .05 & $2.22(2,70)$ & .12 & $1.22(3.54,123.74)$ & .31 \\
\begin{tabular}{l} 
Numerical Pain Rating Scale score \\
\hline
\end{tabular} & $4.58(1.90,133.21)$ & .003 & $0.91(2,70)$ & .41 & $1.84(3.81,133.21)$ & .13 \\
& & .03 & $3.63(2,83)$ & .03 & $4.15(2,83)$ & .02 \\
\hline
\end{tabular}

Table 6. Repeated-measures analysis of variance for the primary outcomes based on the duration of the program.

\begin{tabular}{|c|c|c|c|c|c|c|}
\hline \multirow[t]{3}{*}{ Outcome variable } & \multicolumn{6}{|l|}{ Program duration } \\
\hline & \multicolumn{2}{|l|}{ Time } & \multicolumn{2}{|l|}{ Program duration } & \multicolumn{2}{|c|}{ Time $\times$ program duration } \\
\hline & $F$ test $(d f 1, d f 2)$ & $P$ value & $F$ test $(d f 1, d f 2)$ & $P$ value & $F$ test $(d f 1, d f 2)$ & $P$ value \\
\hline Numerical Pain Rating Scale score & $2.31(1.80,126.07)$ & .11 & $3.03(1,70)$ & .09 & $0.98(1.80,126.07)$ & .37 \\
\hline $\begin{array}{l}\text { Foot and Ankle Ability Measure-activities of } \\
\text { daily living score }\end{array}$ & $3.70(1.89,131.98)$ & .03 & $7.62(1,70)$ & .01 & $0.50(1.88,131.98)$ & .60 \\
\hline Numerical Pain Rating Scale score & $3.97(1,83)$ & .05 & $1.43(1,83)$ & .24 & $2.16(1,83)$ & .14 \\
\hline
\end{tabular}

Overall, patients with sprain grade II experienced the greatest improvement, with outcomes converging in the long term.

Regarding FAAM-Sports scores, it was not possible to account for the 6-month follow-up in the repeated-measures analysis, since $60.8 \%(48 / 79)$ of answers to the FAMM-Sports questionnaire were not applicable during the pandemic period, yielding a very small sample size per subgroup $(\mathrm{n}=18,10$, and 3 for sprain grades I, II, and III, respectively). Outcomes following the end of the program for this dimension revealed a main effect of time $(P=.05)$ and grade of sprain $(P=.03)$ and an interaction between time and grade of sprain $(P=.02)$. Differences among the 3 subgroups were detected at the end of the program ( $P=.01,1$-way ANOVA), with post hoc multiple comparisons showing that patients with grade II sprain scored significantly higher than those with grade III sprain $(P=.01$; mean difference 34.1 points, $95 \%$ CI 6.28-61.94 points). 
Figure 3. Estimated marginal means over time based on (A) sprain grade I, II , and III for NPRS and FAAM-ADL scores ( $\mathrm{n}=45$, 23, and 9, respectively; baseline to 6-month follow-up) and for FAAM-Sports ( $\mathrm{n}=47,24$, and 7, respectively; baseline to the end of the program) and (B) program duration up to 4 weeks and above 4 weeks for NPRS and FASAM-ADL scores (n=39 and 38, respectively; baseline to 6-month follow-up), and for FAAM-Sports $(\mathrm{n}=41$ and 37, respectively; baseline to the end of the program). FAAM-ADL: Foot and Ankle Ability Measure-activities of daily living, FAAM-Sports: Foot and Ankle Ability Measure-sports, NPRS: Numerical Pain Rating Scale.
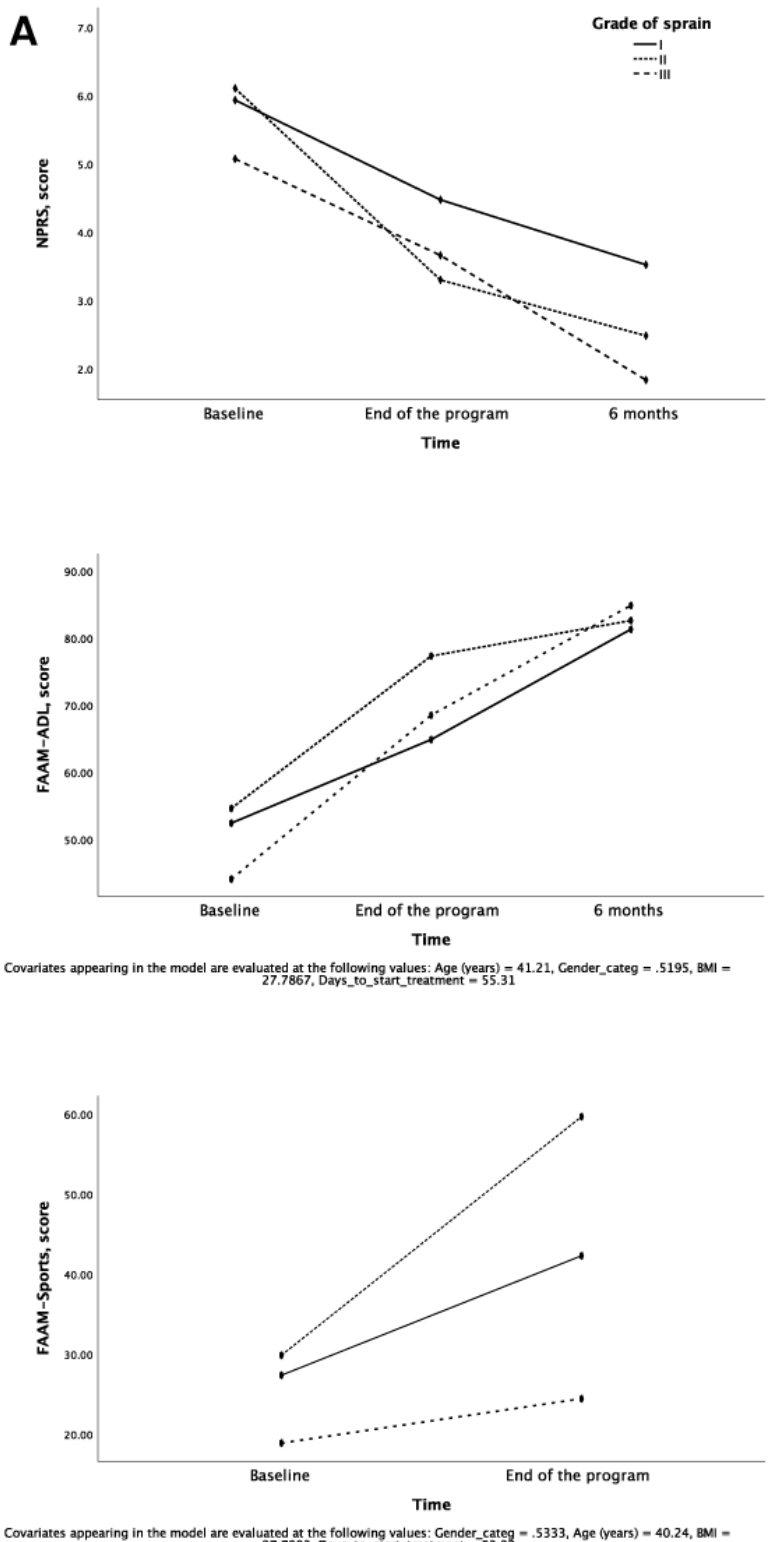

\section{Program Duration}

The mean program duration was 5.0 (SD 3.81, range 0.9-19.9; median 4.1, IQR 5.0; 95\% CI 4.3-5.8) weeks, with over half of the sample $(54.8 \%, 51 / 93)$ discharged within 4 weeks. Hence, a cut-off of 4 weeks was established to explore differences in outcomes between patients discharged before or after that cut-off.

This analysis confirmed a main effect of time and program duration for FAAM-ADL after 6 months $(P=.03$ and $P=.01$, respectively). An effect of time was also observed on FAAM-Sports $(P=.05)$ between baseline and the end of the

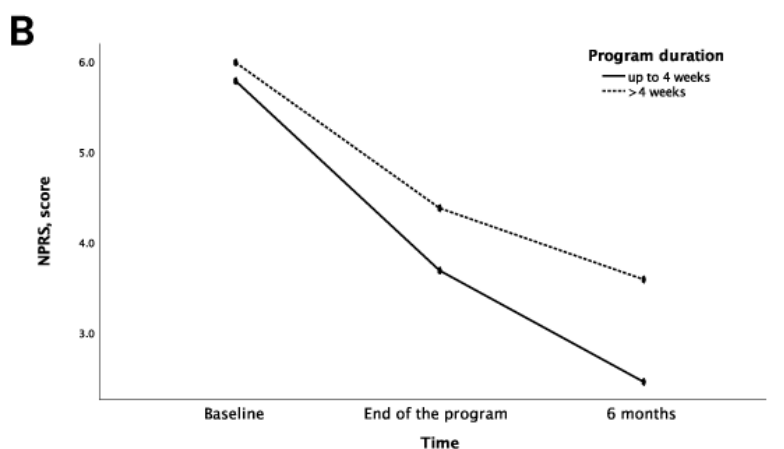

Time
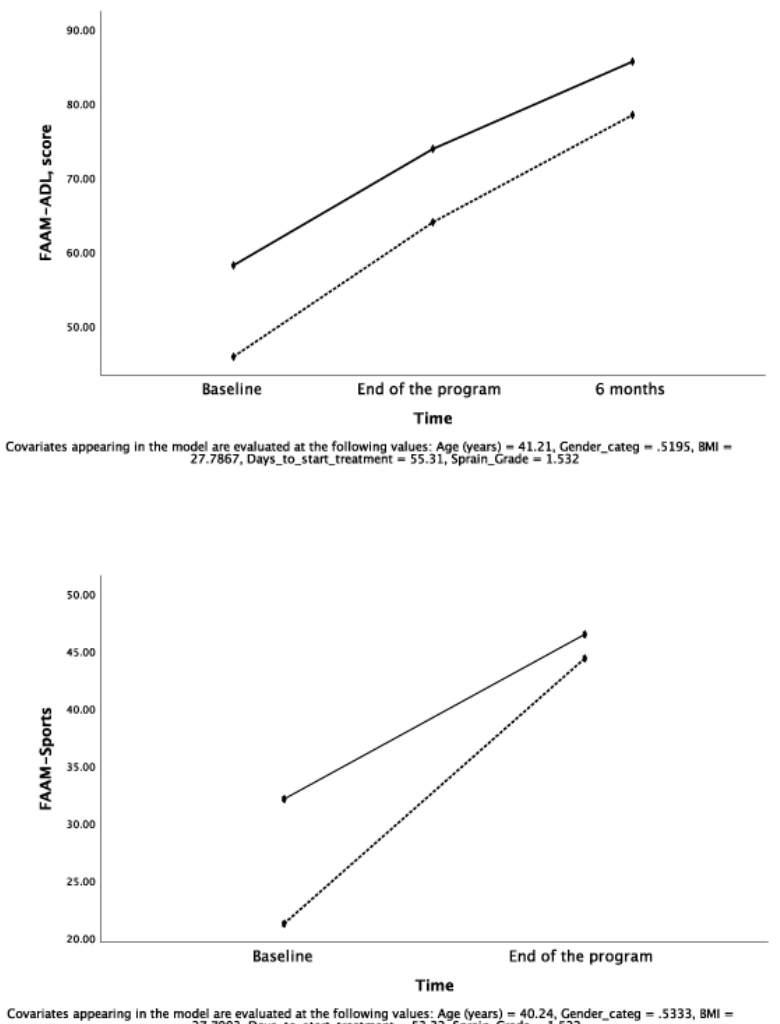

program. No other effects or interactions were detected (Table 5 and Figure 3).

Patients requiring $>4$ weeks of treatment had significantly worse baseline and end-of-program FAAM-ADL scores $(P=.002$ and $P=.02$, respectively; independent samples $t$ test). NPRS was not different at baseline $(P=.76)$, but patients in the $<4$ weeks group reported less pain at the 6-month follow-up assessment $(P=.05$; independent samples $t$ test) along with better functional outcomes ( $P=.03$ for FAAM-ADL; independent samples $t$ test). FAMM-Sports scores were also not different at baseline ( $P=.05$; independent samples $t$ test), and patients in both subgroups recovered similarly for this dimension. 


\section{Discussion}

\section{Principal Findings}

This study shows that a fully remote, home-based, digital rehabilitation program for acute ankle sprains delivered at patients' homes allowed patients to attain clinically meaningful improvement in pain (evident from their VAS and NPRS scores), activities of daily living (FAAM-ADL scores), and sports activities (FAAM-Sports scores). Furthermore, these programs led to a full recovery without residual disability in $83.9 \%$ of patients, which compares favorably with the published literature showing that at least one-third of individuals will experience residual symptoms [13-15].

There is a dearth of studies on digital programs for acute ankle sprains, as supported by recently published systematic [51] and literature [52] reviews on the subject. We therefore broadened the search to include exercise-based approaches in general [23,53-55]. Overall, the results obtained in this study are similar to those reported for other supervised exercise programs, and the first detailed positive outcomes with a fully digital program.

One RCT ( $=90)$ [55] assessed the effectiveness of exercise training using the Nintendo Wii Fit balance board in comparison to physical therapy and to a control receiving no therapy. Investigators found this tool was not more effective than PT only or no exercise. Of note, patients enrolled in this study had little room left for improvement, with near-normal scores at baseline on the FAAM-ADL (mean 71-83) and FAAM-Sports (mean 37-52), and low VAS pain (approximately mean 1 point), which may have been the reason behind no difference between physical therapy only or no exercise.

In another RCT ( $\mathrm{n}=74)$ [54] comparing an manual therapy and exercise (MTEX) program with a home exercise program (HEP), the improvement in the MTEX program at 4 weeks was similar to what we observed in this study: FAAM-ADL score, mean 21.3 (95\% CI 18.2-24.5) points; FAAM-Sports score, mean 27.1 (95\% CI 22.7-31.6) points; and NPRS score, mean -2.7 (95\% CI -2.9 to -2.5 ) points. When compared to the HEP group, our intervention also provided superior outcomes in terms of functional recovery and pain.

Both NPRS baseline values and its magnitude of change from baseline to the end of the program were similar to the ones reported for other exercise interventions after ankle sprain $[23,54,56]$.

\section{Recurrence and Completeness of Recovery}

This study corroborates previous findings of high recurrence rates both among nonathlete $(24 \%-54 \%)$ [57,58] and athlete (12\%-47\%) populations, with $29 \%$ of all enrolled patients having had previous injury.

Also consistent with our findings, the group from Verhagen found that a home-based proprioceptive 8-week training program, delivered through a mobile app after usual care, was successful in reducing recurrences of ankle sprains in a 12 -month period as against conventional care alone (22\% versus $33 \%$, as revealed through an RCT with 522 athletes from the Netherlands) [59]. Although the rate of reinjury was still much higher than that reported here at 6 months $(2.5 \%)$, this further supports the effectiveness of remote interventions in preventing ankle reinjuries.

Previous findings indicate an association between the rate of resprain and incomplete recovery [57]. Therefore, the high percentage of complete recovery attained in this study may explain the lower rate of recurrence, even if the 2 patients who experienced recurrence had been discharged with no residual disability. In fact, by the 6-month follow-up, 45.6\% (36/79) and $35.5 \%(11 / 31)$ of patients in this study, respectively, achieved scores compatible with the normative values for FAAM-ADL and FAAM-Sports reported for the adult population (92.3 and 85.1 points, respectively) [60].

\section{Training Volume}

In a systematic review and meta-analysis, Bleakley et al [61] found no clear consensus on an optimal training volume, with rehabilitation times ranging from 3.5 to 21 hours (median 12 hours). The highest total rehabilitation time was 21 hours, equivalent to 1.75 hours per week over 12 weeks. In our study, the mean total exercising time was 12.5 (SD 10.50, range 1.3-47.3) hours, equivalent to 2.4 (SD 0.87, range 0.4-4.6) hours per week. Hence, the total training volume was similar to that of other interventions, but dosage per week was much higher.

\section{Subgroup Outcomes}

Even though overall changes from baseline to follow-up were not significantly different between patients discharged before or after 4 weeks (no interaction found between time and program duration), the latter patients had worse FAAM-ADL scores both prior to participating in the program and at discharge, and worse NPRS and FAAM-ADL scores at 6 months.

We hypothesize this could be a consequence of the particularly long period between the injury date and treatment initiation-mean 53.2 (SD 48.26, range 4-281) days-mainly in relation to disruptions in health care delivery in the wake of the COVID-19 pandemic. (ie, a delay between injury and the physician appointment) (Table 1). Indeed, we found a correlation between longer waiting periods and extended program duration (Pearson $r_{93}=0.48 ; P<.001$ ), with mean waiting times of 40.9 (SD 38.79) days for patients who were discharged within 4 weeks versus 68.1 (SD 54.57) days for those discharged after 4 weeks $(P=.01)$.

Recent reviews have not found sufficient evidence regarding independent predictors of clinical outcomes [62,63]. Only 1 study so far gathered proof that a low injury grade is a predictor for better outcomes [64].

In this study, no differences were found in terms of program duration between injury grades $(P=.11,1$-way ANOVA; grade I: 4.8 weeks, $95 \%$ CI 3.8-5.8 weeks; grade II: 4.7 weeks, $95 \%$ CI 3.2-6.2 weeks; grade III: 7.5 weeks, 95\% CI 3.7-11.2 weeks). Nonetheless, we found differences between injury grade and clinical improvement. Patients with grade II injuries experienced the greatest improvement during the program, followed by those with grade I and then grade III injuries. This could be explained by the fact that grade I sprains are only directed to physical therapy in case of aggravation, at a point where they actually 
become slower respondents. In the long term, however, patients with grade III sprain reported the greatest improvement in NPRS and FAAM-Sports scores, followed by those with grade II and grade I sprain, as confirmed by LMM analysis. This is most likely related to the lower FAAM scores and higher pain levels at baseline in patients with grade III sprain, consequently with a higher margin of progression. These aspects, along with the convergence of clinical outcomes over time for the 3 groups, do not support the notion of a low injury grade being a predictor for better outcomes.

\section{Limitations}

The limitations of this study are mainly related to the study design and the referral process. This was a prospective cohort study and, as such, did not include a control group. However, as shown above, our results are comparable to those reported previously for supervised exercise programs in this same context. Regarding the referral process, while patient assignment to an in-network provider was largely performed administratively, explicit referral to digital programs was possible. This may have introduced a selection bias toward patients more likely to engage in digital care.

\section{Conclusions}

This was the first study presenting the outcomes from a fully remote exercise-based rehabilitation program for acute ankle sprains, demonstrating clinically meaningful change in both pain and function, as well as complete recovery in $81.7 \%$ of patients, with sustained results over time. As such, this study demonstrates not only the feasibility of fully digital programs in this context, but also that these programs can achieve clinical outcomes comparable to face-to-face interventions.

\section{Acknowledgments}

The authors acknowledge Ivo Gabriel, Ricardo Gomes, and Tiago Seabra, who extracted the data from the databases. The authors also acknowledge Tranquilidade Seguros for partnering with SWORD Health Technologies, Inc, and providing access to this study population.

\section{Conflicts of Interest}

FDC, MM, SL, DJ, DC, CN, and VB are employees at SWORD Health Technologies, Inc, the study sponsor. GEF and JL are scientific advisors at SWORD Health Technologies, Inc.

\section{Multimedia Appendix 1}

Fully remote rehabilitation protocol applied for acute ankle sprains.

[DOCX File, 16 KB-Multimedia Appendix 1]

\section{Multimedia Appendix 2}

De-identified participants data.

[XLSX File (Microsoft Excel File), 50 KB-Multimedia Appendix 2]

\section{Multimedia Appendix 3}

Support statistical analysis tables.

[DOCX File, 25 KB-Multimedia Appendix 3]

\section{Multimedia Appendix 4}

Adverse events list.

[DOCX File, 13 KB-Multimedia Appendix 4]

\section{References}

1. Waterman BR, Owens BD, Davey S, Zacchilli MA, Belmont PJ. The epidemiology of ankle sprains in the United States. J Bone Joint Surg Am 2010 Oct 06;92(13):2279-2284. [doi: 10.2106/JBJS.I.01537] [Medline: 20926721]

2. Bridgman SA, Clement D, Downing A, Walley G, Phair I, Maffulli N. Population based epidemiology of ankle sprains attending accident and emergency units in the West Midlands of England, and a survey of UK practice for severe ankle sprains. Emerg Med J 2003 Nov;20(6):508-510 [FREE Full text] [doi: 10.1136/emj.20.6.508] [Medline: 14623833]

3. Shah S, Thomas AC, Noone JM, Blanchette CM, Wikstrom EA. Incidence and Cost of Ankle Sprains in United States Emergency Departments. Sports Health 2016;8(6):547-552 [FREE Full text] [doi: 10.1177/1941738116659639] [Medline: 27474161]

4. Doherty C, Delahunt E, Caulfield B, Hertel J, Ryan J, Bleakley C. The incidence and prevalence of ankle sprain injury: a systematic review and meta-analysis of prospective epidemiological studies. Sports Med 2014 Jan;44(1):123-140. [doi: 10.1007/s40279-013-0102-5] [Medline: 24105612] 
5. Gribble PA, Bleakley CM, Caulfield BM, Docherty CL, Fourchet F, Fong DT, et al. Evidence review for the 2016 International Ankle Consortium consensus statement on the prevalence, impact and long-term consequences of lateral ankle sprains. Br J Sports Med 2016 Dec;50(24):1496-1505. [doi: 10.1136/bjsports-2016-096189] [Medline: 27259753]

6. Bielska IA, Wang X, Lee R, Johnson AP. The health economics of ankle and foot sprains and fractures: A systematic review of English-language published papers. Part 2: The direct and indirect costs of injury. Foot (Edinb) 2019 Jun;39:115-121. [doi: 10.1016/j.foot.2017.07.003] [Medline: 29174064]

7. Knowles SB, Marshall SW, Miller T, Spicer R, Bowling JM, Loomis D, et al. Cost of injuries from a prospective cohort study of North Carolina high school athletes. Inj Prev 2007 Dec;13(6):416-421 [FREE Full text] [doi: $\underline{10.1136 / i p .2006 .014720]}$ [Medline: $\underline{18056320]}$

8. Roos KG, Kerr ZY, Mauntel TC, Djoko A, Dompier TP, Wikstrom EA. The Epidemiology of Lateral Ligament Complex Ankle Sprains in National Collegiate Athletic Association Sports. Am J Sports Med 2017 Jan;45(1):201-209. [doi: 10.1177/0363546516660980] [Medline: 27573356]

9. Attenborough AS, Hiller CE, Smith RM, Stuelcken M, Greene A, Sinclair PJ. Chronic ankle instability in sporting populations. Sports Med 2014 Nov;44(11):1545-1556. [doi: 10.1007/s40279-014-0218-2] [Medline: 24981244]

10. Jain N, Murray D, Kemp S, Calder J. Frequency and trends in foot and ankle injuries within an English Premier League Football Club using a new impact factor of injury to identify a focus for injury prevention. Foot Ankle Surg 2014 Dec;20(4):237-240. [doi: 10.1016/j.fas.2014.05.004] [Medline: 25457658]

11. Kemler E, Thijs KM, Badenbroek I, van de Port IGL, Hoes AW, Backx FJG. Long-term prognosis of acute lateral ankle ligamentous sprains: high incidence of recurrences and residual symptoms. Fam Pract 2016 Dec;33(6):596-600. [doi: 10.1093/fampra/cmw076] [Medline: 27535328]

12. Pasanen K, Ekola T, Vasankari T, Kannus P, Heinonen A, Kujala UM, et al. High ankle injury rate in adolescent basketball: A 3-year prospective follow-up study. Scand J Med Sci Sports 2017 Jun;27(6):643-649. [doi: 10.1111/sms.12818] [Medline: 28033652]

13. Fong DT, Hong Y, Chan L, Yung PS, Chan K. A systematic review on ankle injury and ankle sprain in sports. Sports Med 2007;37(1):73-94. [doi: 10.2165/00007256-200737010-00006] [Medline: 17190537]

14. Hiller CE, Nightingale EJ, Raymond J, Kilbreath SL, Burns J, Black DA, et al. Prevalence and impact of chronic musculoskeletal ankle disorders in the community. Arch Phys Med Rehabil 2012 Oct;93(10):1801-1807. [doi: 10.1016/j.apmr.2012.04.023] [Medline: 22575395]

15. Swenson DM, Collins CL, Fields SK, Comstock RD. Epidemiology of U.S. high school sports-related ligamentous ankle injuries, 2005/06-2010/11. Clin J Sport Med 2013 May;23(3):190-196 [FREE Full text] [doi: 10.1097/JSM.0b013e31827d21fe] [Medline: 23328403]

16. van Rijn RM, van Os AG, Bernsen RMD, Luijsterburg PA, Koes BW, Bierma-Zeinstra SMA. What is the clinical course of acute ankle sprains? A systematic literature review. Am J Med 2008 Apr;121(4):324-331.e6. [doi:

10.1016/j.amjmed.2007.11.018] [Medline: 18374692]

17. Zech A, Hübscher M, Vogt L, Banzer W, Hänsel F, Pfeifer K. Neuromuscular training for rehabilitation of sports injuries: a systematic review. Med Sci Sports Exerc 2009 Oct;41(10):1831-1841. [doi: 10.1249/MSS.0b013e3181a3cf0d] [Medline: 19727032]

18. Doherty C, Bleakley C, Delahunt E, Holden S. Treatment and prevention of acute and recurrent ankle sprain: an overview of systematic reviews with meta-analysis. Br J Sports Med 2017 Jan;51(2):113-125. [doi: 10.1136/bjsports-2016-096178] [Medline: 28053200]

19. Postle K, Pak D, Smith TO. Effectiveness of proprioceptive exercises for ankle ligament injury in adults: a systematic literature and meta-analysis. Man Ther 2012 Aug;17(4):285-291. [doi: 10.1016/j.math.2012.02.016] [Medline: 22459604]

20. van Os AG, Bierma-Zeinstra SMA, Verhagen AP, de Bie RA, Luijsterburg PAJ, Koes BW. Comparison of conventional treatment and supervised rehabilitation for treatment of acute lateral ankle sprains: a systematic review of the literature. $\mathbf{J}$ Orthop Sports Phys Ther 2005 Feb;35(2):95-105. [doi: 10.2519/jospt.2005.35.2.95] [Medline: 15773567]

21. van Rijn RM, van Ochten J, Luijsterburg PAJ, van Middelkoop M, Koes BW, Bierma-Zeinstra SMA. Effectiveness of additional supervised exercises compared with conventional treatment alone in patients with acute lateral ankle sprains: systematic review. BMJ 2010 Oct 26;341:c5688 [FREE Full text] [doi: 10.1136/bmj.c5688] [Medline: 20978065]

22. Zöch C, Fialka-Moser V, Quittan M. Rehabilitation of ligamentous ankle injuries: a review of recent studies. Br J Sports Med 2003 Aug;37(4):291-295 [FREE Full text] [doi: 10.1136/bjsm.37.4.291] [Medline: 12893710]

23. Bleakley CM, O'Connor SR, Tully MA, Rocke LG, Macauley DC, Bradbury I, et al. Effect of accelerated rehabilitation on function after ankle sprain: randomised controlled trial. BMJ 2010 May 10;340:c1964. [doi: 10.1136/bmj.c1964] [Medline: 20457737]

24. Bleakley CM, McDonough SM, MacAuley DC. Some conservative strategies are effective when added to controlled mobilisation with external support after acute ankle sprain: a systematic review. Aust J Physiother 2008;54(1):7-20. [doi: 10.1016/s0004-9514(08)70061-8] [Medline: 18298355]

25. Petersen W, Rembitzki IV, Koppenburg AG, Ellermann A, Liebau C, Brüggemann GP, et al. Treatment of acute ankle ligament injuries: a systematic review. Arch Orthop Trauma Surg 2013 Aug;133(8):1129-1141 [FREE Full text] [doi: 10.1007/s00402-013-1742-5] [Medline: 23712708] 
26. Jesus TS, Landry MD, Dussault G, Fronteira I. Human resources for health (and rehabilitation): Six Rehab-Workforce Challenges for the century. Hum Resour Health 2017 Jan 23;15(1):8 [FREE Full text] [doi: 10.1186/s12960-017-0182-7] [Medline: 28114960]

27. Dew A, Bulkeley K, Veitch C, Bundy A, Gallego G, Lincoln M, et al. Addressing the barriers to accessing therapy services in rural and remote areas. Disabil Rehabil 2013 Aug;35(18):1564-1570. [doi: 10.3109/09638288.2012.720346] [Medline: 23009191]

28. Zimbelman JL, Juraschek SP, Zhang X, Lin VW. Physical therapy workforce in the United States: forecasting nationwide shortages. PM R 2010 Nov;2(11):1021-1029. [doi: 10.1016/j.pmrj.2010.06.015] [Medline: 21093838]

29. Wong ST, Regan S. Patient perspectives on primary health care in rural communities: effects of geography on access, continuity and efficiency. Rural Remote Health 2009;9(1):1142 [FREE Full text] [Medline: 19298094]

30. Wester JU, Jespersen SM, Nielsen KD, Neumann L. Wobble board training after partial sprains of the lateral ligaments of the ankle: a prospective randomized study. J Orthop Sports Phys Ther 1996 May;23(5):332-336. [doi: 10.2519/jospt.1996.23.5.332] [Medline: 8728532]

31. Feger MA, Herb CC, Fraser JJ, Glaviano N, Hertel J. Supervised rehabilitation versus home exercise in the treatment of acute ankle sprains: a systematic review. Clin Sports Med 2015 Apr;34(2):329-346. [doi: 10.1016/j.csm.2014.12.001] [Medline: 25818717]

32. Hansen S, Aaboe J, Mechlenburg I, Overgaard S, Mikkelsen LR. Effects of supervised exercise compared to non-supervised exercise early after total hip replacement on patient-reported function, pain, health-related quality of life and performance-based function - a systematic review and meta-analysis of randomized controlled trials. Clin Rehabil 2019 Jan;33(1):13-23. [doi: 10.1177/0269215518791213] [Medline: $\underline{30073856]}$

33. van Egmond MA, van der Schaaf M, Vredeveld T, Vollenbroek-Hutten MMR, van Berge Henegouwen MI, Klinkenbijl JHG, et al. Effectiveness of physiotherapy with telerehabilitation in surgical patients: a systematic review and meta-analysis. Physiotherapy 2018 Sep;104(3):277-298. [doi: 10.1016/j.physio.2018.04.004] [Medline: 30030037]

34. Grona SL, Bath B, Busch A, Rotter T, Trask C, Harrison E. Use of videoconferencing for physical therapy in people with musculoskeletal conditions: A systematic review. J Telemed Telecare 2018 Jun;24(5):341-355. [doi: 10.1177/1357633X17700781] [Medline: 28403669]

35. Kairy D, Lehoux P, Vincent C, Visintin M. A systematic review of clinical outcomes, clinical process, healthcare utilization and costs associated with telerehabilitation. Disabil Rehabil 2009;31(6):427-447. [doi: 10.1080/09638280802062553] [Medline: 18720118]

36. Russell TG, Blumke R, Richardson B, Truter P. Telerehabilitation mediated physiotherapy assessment of ankle disorders. Physiother Res Int 2010 Sep;15(3):167-175. [doi: 10.1002/pri.471] [Medline: 20812313]

37. Russell TG, Buttrum P, Wootton R, Jull GA. Internet-based outpatient telerehabilitation for patients following total knee arthroplasty: a randomized controlled trial. J Bone Joint Surg Am 2011 Jan 19;93(2):113-120. [doi: 10.2106/JBJS.I.01375] [Medline: 21248209]

38. Pastora-Bernal JM, Martín-Valero R, Barón-López FJ, Estebanez-Pérez MJ. Evidence of Benefit of Telerehabitation After Orthopedic Surgery: A Systematic Review. J Med Internet Res 2017 Apr 28;19(4):e142 [FREE Full text] [doi: 10.2196/jmir.6836] [Medline: 28455277]

39. Cottrell MA, Galea OA, O'Leary SP, Hill AJ, Russell TG. Real-time telerehabilitation for the treatment of musculoskeletal conditions is effective and comparable to standard practice: a systematic review and meta-analysis. Clin Rehabil 2017 May;31(5):625-638. [doi: 10.1177/0269215516645148] [Medline: 27141087]

40. Horsley S, Schock G, Grona SL, Montieth K, Mowat B, Stasiuk K, et al. Use of real-time videoconferencing to deliver physical therapy services: A scoping review of published and emerging evidence. J Telemed Telecare 2020 Dec;26(10):581-589. [doi: 10.1177/1357633X19854647] [Medline: 31213166]

41. Mani S, Sharma S, Omar B, Paungmali A, Joseph L. Validity and reliability of Internet-based physiotherapy assessment for musculoskeletal disorders: a systematic review. J Telemed Telecare 2017 Apr;23(3):379-391. [doi: 10.1177/1357633X16642369] [Medline: 27036879]

42. Ee Chin LC, Basah S, Affandi M, Shah M, Yaacob S, Ewe Juan Y, et al. Home-based ankle rehabilitation system: Literature review and evaluation. Jurnal Teknologi 2017 Aug 28;79(6). [doi: 10.11113/jt.v79.8468]

43. Correia FD, Nogueira A, Magalhães I, Guimarães J, Moreira M, Barradas I, et al. Home-based Rehabilitation With A Novel Digital Biofeedback System versus Conventional In-person Rehabilitation after Total Knee Replacement: a feasibility study. Sci Rep 2018 Jul 26;8(1):11299 [FREE Full text] [doi: 10.1038/s41598-018-29668-0] [Medline: $\underline{30050087]}$

44. Correia FD, Nogueira A, Magalhães I, Guimarães J, Moreira M, Barradas I, et al. Medium-Term Outcomes of Digital Versus Conventional Home-Based Rehabilitation After Total Knee Arthroplasty: Prospective, Parallel-Group Feasibility Study. JMIR Rehabil Assist Technol 2019 Feb 28;6(1):e13111 [FREE Full text] [doi: 10.2196/13111] [Medline: 30816849]

45. Dias Correia F, Nogueira A, Magalhães I, Guimarães J, Moreira M, Barradas I, et al. Digital Versus Conventional Rehabilitation After Total Hip Arthroplasty: A Single-Center, Parallel-Group Pilot Study. JMIR Rehabil Assist Technol 2019 Jun 21;6(1):e14523 [FREE Full text] [doi: 10.2196/14523] [Medline: 31228176]

46. Luís S. Adaptação e validação da Foot and Ankle Ability Measure para a população portuguesa. Coimbra Health School. 2017. URL: http://hdl.handle.net/10400.26/18541 [accessed 2021-09-15] 
47. Krueger C, Tian L. A comparison of the general linear mixed model and repeated measures ANOVA using a dataset with multiple missing data points. Biol Res Nurs 2004 Oct;6(2):151-157. [doi: 10.1177/1099800404267682] [Medline: 15388912]

48. Azur MJ, Stuart EA, Frangakis C, Leaf PJ. Multiple imputation by chained equations: what is it and how does it work? Int J Methods Psychiatr Res 2011 Mar;20(1):40-49 [FREE Full text] [doi: 10.1002/mpr.329] [Medline: 21499542]

49. Lynch SA. Assessment of the Injured Ankle in the Athlete. J Athl Train 2002 Dec;37(4):406-412 [FREE Full text] [Medline: 12937562]

50. Martin RL, Irrgang JJ, Burdett RG, Conti SF, Van Swearingen JM. Evidence of validity for the Foot and Ankle Ability Measure (FAAM). Foot Ankle Int 2005 Nov;26(11):968-983. [doi: 10.1177/107110070502601113] [Medline: 16309613]

51. Ortega-Avila AB, Cervera-Garvi P, Marchena-Rodriguez A, Chicharro-Luna E, Nester CJ, Starbuck C, et al. Conservative Treatment for Acute Ankle Sprain: A Systematic Review. J Clin Med 2020 Sep 27;9(10):3128 [FREE Full text] [doi: 10.3390/jcm9103128] [Medline: $\underline{\text { 32992655] }}$

52. Bleakley CM, Matthews M, Smoliga JM. Most ankle sprain research is either false or clinically unimportant: A 30-year audit of randomized controlled trials. J Sport Health Sci 2020 Nov 11 [FREE Full text] [doi: 10.1016/j.jshs.2020.11.002] [Medline: $\underline{33188966}$ ]

53. Tran K, McCormack S. Exercise for the Treatment of Ankle Sprain: A Review of Clinical Effectiveness and Guidelines [Internet]. CADTH Rapid Response Reports 2020. [Medline: 33074633]

54. Cleland JA, Mintken PE, McDevitt A, Bieniek ML, Carpenter KJ, Kulp K, et al. Manual physical therapy and exercise versus supervised home exercise in the management of patients with inversion ankle sprain: a multicenter randomized clinical trial. J Orthop Sports Phys Ther 2013;43(7):443-455. [doi: 10.2519/jospt.2013.4792] [Medline: 23628755]

55. Punt IM, Ziltener J, Monnin D, Allet L. Wii Fit ${ }^{\mathrm{TM}}$ exercise therapy for the rehabilitation of ankle sprains: Its effect compared with physical therapy or no functional exercises at all. Scand J Med Sci Sports 2016 Jul;26(7):816-823. [doi: 10.1111/sms.12509] [Medline: 26076737]

56. Truyols-Domí Nguez S, Salom-Moreno J, Abian-Vicen J, Cleland JA, Fernández-de-Las-Peñas C. Efficacy of thrust and nonthrust manipulation and exercise with or without the addition of myofascial therapy for the management of acute inversion ankle sprain: a randomized clinical trial. J Orthop Sports Phys Ther 2013 May;43(5):300-309. [doi: 10.2519/jospt.2013.4467] [Medline: 23485845]

57. van Middelkoop M, van Rijn RM, Verhaar JAN, Koes BW, Bierma-Zeinstra SMA. Re-sprains during the first 3 months after initial ankle sprain are related to incomplete recovery: an observational study. J Physiother 2012;58(3):181-188 [FREE Full text] [doi: 10.1016/S1836-9553(12)70109-1] [Medline: 22884185]

58. Verhagen RA, de Keizer G, van Dijk CN. Long-term follow-up of inversion trauma of the ankle. Arch Orthop Trauma Surg 1995;114(2):92-96. [doi: 10.1007/BF00422833] [Medline: 7734241]

59. Hupperets MDW, Verhagen EALM, van Mechelen W. Effect of unsupervised home based proprioceptive training on recurrences of ankle sprain: randomised controlled trial. BMJ 2009 Jul 09;339:b2684 [FREE Full text] [doi: 10.1136/bmj.b2684] [Medline: 19589822]

60. Matheny LM, Gittner K, Harding J, Clanton TO. Patient Reported Outcome Measures in the Foot and Ankle: Normative Values Do Not Reflect 100\% Full Function. Knee Surg Sports Traumatol Arthrosc 2021 Apr;29(4):1276-1283. [doi: 10.1007/s00167-020-06069-3] [Medline: 32468128]

61. Bleakley CM, Taylor JB, Dischiavi SL, Doherty C, Delahunt E. Rehabilitation Exercises Reduce Reinjury Post Ankle Sprain, But the Content and Parameters of an Optimal Exercise Program Have Yet to Be Established: A Systematic Review and Meta-analysis. Arch Phys Med Rehabil 2019 Jul;100(7):1367-1375. [doi: 10.1016/j.apmr.2018.10.005] [Medline: $\underline{30612980]}$

62. Thompson JY, Byrne C, Williams MA, Keene DJ, Schlussel MM, Lamb SE. Prognostic factors for recovery following acute lateral ankle ligament sprain: a systematic review. BMC Musculoskelet Disord 2017 Oct 23;18(1):421 [FREE Full text] [doi: 10.1186/s12891-017-1777-9] [Medline: 29061135]

63. Ferreira JN, Vide J, Mendes D, Protásio J, Viegas R, Sousa MR. Prognostic factors in ankle sprains: a review. EFORT Open Rev 2020 Jun;5(6):334-338 [FREE Full text] [doi: 10.1302/2058-5241.5.200019] [Medline: 32655888]

64. Langner I, Frank M, Kuehn JP, Hinz P, Ekkernkamp A, Hosten N, et al. Acute inversion injury of the ankle without radiological abnormalities: assessment with high-field MR imaging and correlation of findings with clinical outcome. Skeletal Radiol 2011 Apr;40(4):423-430. [doi: 10.1007/s00256-010-1017-y] [Medline: 20706714]

\section{Abbreviations}

ANOVA: analysis of variance

FAAM-ADL: Foot and Ankle Ability Measure-activities of daily living

FAAM-Sports: Foot and Ankle Ability Measure-sports

HEP: home exercise program

LMM: linear mixed-effects model

MTEX: manual therapy and exercise

NPRS: Numerical Pain Rating Scale 
RCT: randomized controlled trial

VAS: visual analogue scale

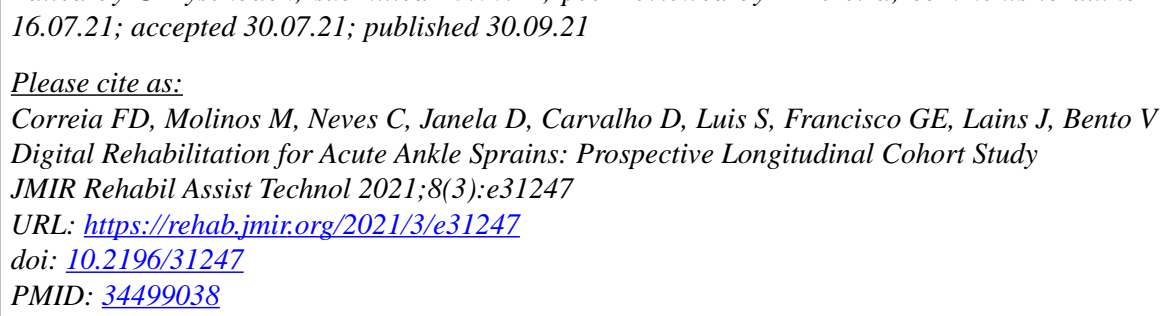

CFernando D Correia, Maria Molinos, Carlos Neves, Dora Janela, Diana Carvalho, Sara Luis, Gerard E Francisco, Jorge Lains, Virgilio Bento. Originally published in JMIR Rehabilitation and Assistive Technology (https://rehab.jmir.org), 30.09.2021. This is an open-access article distributed under the terms of the Creative Commons Attribution License (https://creativecommons.org/licenses/by/4.0/), which permits unrestricted use, distribution, and reproduction in any medium, provided the original work, first published in JMIR Rehabilitation and Assistive Technology, is properly cited. The complete bibliographic information, a link to the original publication on https://rehab.jmir.org/, as well as this copyright and license information must be included. 